\title{
Enhancement in Performance of Parabolic Trough Collector with Serrated Twisted-tape Inserts
}

\author{
Atwari Rawani $^{1 *}$, S.P.Sharma ${ }^{2}$, K.D.P.Singh ${ }^{3}$ \\ 1,2,3 Department of Mechanical Engineering, \\ National Institute of Technology, Jamshedpur, Jharkhand, India, Pin-831014 \\ E-mail:!rawani.jay@gmail.com
}

Received 11 December 2016, Revised 07 February 2017, Accepted 17 February 2017

\begin{abstract}
The aim of this study is to analytically investigate the performance of parabolic trough collector (PTC) with serrated twisted tape insert in the absorber tube. The heat transfer equations for fully developed flow under quasi-steady state conditions have been developed in order to analyze entropy generation, exergy efficiency, thermal efficiency, rise in fluid temperature and to study the effect of system and operating parameters on performance. A computer program, based on mathematical models is developed in $\mathrm{C}^{++}$language to estimate the temperature rise of fluid for evaluation of performances under specified conditions. For numerical simulations four different twist ratio, $\mathrm{x}=1,2,3,4$ and mass flow rate $0.06 \mathrm{~kg} / \mathrm{s}$ to $0.16 \mathrm{~kg} / \mathrm{s}(3000 \leq \operatorname{Re} \leq 9000)$ are used. This study shows that twisted tape insert when used shows great promise for enhancing the performance of PTC. Results show that for $\mathrm{x}=1$, Nusselt number/heat transfer coefficient is found to be 4.38 and 3.51 times over plain absorber of PTC at mass flow rate of $0.06 \mathrm{~kg} / \mathrm{s}$ and 0.16 $\mathrm{kg} / \mathrm{s}$ respectively; while corresponding enhancement in thermal efficiency is $15.7 \%$ and $5.41 \%$ respectively. Also the exergy efficiency has been found to be $12.10 \%$ and $12.62 \%$ and enhancement factor is 1.157 and 1.053 for same set of conditions.
\end{abstract}

\section{Keywords: Collector efficiency factor; collector heat removal factor; useful heat gain; efficiency.}

\section{Introduction}

The worldwide energy demand is increasing day by day due to rapid industrialization. The world's energy demands fulfill more than $90 \%$ by fossil fuels. The fossil fuels are limited, exhaustable and non-renewable and they create environment pollution. The combustion of fossil fuels produces carbon dioxide; it is one of the greenhouse gases contributing to global warming. On the other hand use of renewable energy resources, can prime to decrease in fossil fuels consumption, inexhustable, sustainable, creates zero or few greenhouse gas emissions and will never run out with negligible impact on the environment.

Solar energy is one of the largest renewable energy resources. The greatest advantage of the solar energy is that it is easily available and abundant. Parabolic trough collectors (PTCs) are one of the main solar heat collector elements, which can be applied for light structure and lowcost systems for producing heat up to $400^{\circ} \mathrm{C}$.

The solar collector tube is a basic component in parabolic trough solar thermal generation system which converts solar radiation into thermal energy. The collector tube consists of an inner metal absorber tube and the outer glass cover tube. The solar radiation is redirected and concentrated on a linear receiver in focal line. The concentrator reflects solar radiation to the outer surface of the inner tube and is absorbed by tube wall. Then, a bulk of the energy will be accompanied to the inner surface of the inner tube and is transferred from the working fluid in inner tubes with the mixed convective heat transfer. Parabolic trough collectors are attractive solar energy collection device for attaining high temperature. The performances of parabolic trough collector can be enhanced by using heat transfer augmentation techniques such as strips, coiled wires, various kinds of twisted tape inserted inside the absorber tube. Bhattacharyya et al. [1] investigated the Nusselt number and the friction factor for laminar flow through a circular duct having roughness of integral transfer rib and fitted with center-cleared twisted-tape. They obtained high Prantdl number ranges from 235- 537 at twist ratio 2.5 and servotherm medium oil. In laminar flow, the combination of center-cleared twisted tape and integral transfer rib having better perform than the individual heat transfer enhancement technique in a certain level of centerclearance. Almanza et al. [2] investigated numerically the performance of parabolic trough collector in direct steam generation under different experimental conditions. Singh and Sulaiman [3] carried out the design procedures of a solar cylindrical parabolic trough concentrator. Ghadirijafarbegloo et al. [4] investigated the convection heat transfer coefficient in parabolic trough collector with perforated louvered twisted tape inserts. They validated the experimental data for three different twisted tape ratios 2.67, 4 and 5.33. They determined the heat transfer rate and pressure drop for fully developed condition and different Reynolds number. The result shows that the heat transfer and friction factor enhances in comparison to a typical plain twisted tape in tube. Wang and Sunder [5] investigated that the heat transfer coefficient in a circular duct with twisted tape inserts. The enhancement of heat transfer coefficient were 30 and 3.5 times to plain tube value in Reynolds number $(\operatorname{Re}<2000)$ and $(5000<\operatorname{Re}<45000)$ respectively. Nagarajan and Sivashanmugam [6] carried out a study on the heat transfer in a circular tube with right left helical twisted tape with spacer inserts by using the CFD analysis. 
The half-length twisted tape equipped with U-bend double pipe heat exchanger for heat transfer and pressure drop analyzed by Yadav [7]. The enhancement of heat transfer coefficient was $40 \%$ higher than typical heat exchanger and thermal performances of full length twisted tape were better than half-length twisted tape. Jaisankar et al. [8] investigated experimentally solar water heater fitted with rods and spacer at the trailing edge of the twisted tape for different length and twist ratios system to analyze the the heat transfer and friction factor characteristic. Enhancement of heat transfer coefficient reduced by $17 \%$ and $29 \%$ for twisted tape with rod and spacer respectively as compared with full length twisted tape. Rose and Briggs [9] experimentally investigated convective heat transfer for several components used in passive techniques in the range of Reynolds number from 5000-45000 and Prandtl number.07-30. The maximum enhancement in heat transfer coefficient is 3.5 and 2.0 for twisted tape and wire coil in comparison to plain. Hejazi et al. [12] experimentally investigated the heat transfer and pressure drop for a tube with twisted tape inserts of twist ratio 6, 9, 12 and 15 . The best thermal performance and heat transfer enhancement as been achieved with twisted tape ratio 6 and 9. Eiasma-ard and Promvonge [13] experimentally investigated the enhancement of heat transfer with alternative clockwise and counter clockwise twisted tape inserts in circular tube. Their results showed that heat transfer enhancement of alternative clockwise and counter clockwise twisted tape with typical twisted tape and plain tube are 12.8-41.9\% and 27.3-90.5\% respectively. Ferroni et al. [14] experimentally investigated the isothermal pressure drop with separated, multiple, short length twisted tape inserts in the horizontal round tube. Their results indicate that pressure drop with full length twisted tape were $50 \%$ higher than multiple short length twisted tapes. V. Zimparov [15] investigated the heat transfer coefficient in a corrugated tube inserts of twisted tape. The enhancement of heat transfer coefficient $1.9-9.6$ is observed in comparison to plain tube in the range of Reynolds number 3000-60000. Wei Liu et al.[16] carried out an experimental study for the enhancement of heat transfer and friction factor for center cleared and short width twisted tape in laminar flows and found that central cleared twisted tape have better performance. Under the uniform wall heat flux condition, the influences of the tube with perforated twisted tape were experimentally investigated by Thianpong et al. [17]. Their results show that the maximum heat transfer in twisted tape is with the bigger holes diameter, more space between the holes and smaller twist tape ratio than plain tube and the typical tape inserts are $27.4 \%$ and $86.7 \%$ respectively.

Based on the above literature review no parametric studies are carried out for an absorber tube of parabolic trough collector with serrated twisted tape inserts for Therminol VP-1 fluid. The present paper analytically investigated the performance enhancement of parabolic trough collector with serrated twisted tape inserts in absorber tube. The effect of mass flow rate on collector efficiency factor, collector heat removal factor, useful heat gain and efficiency have been reported.

\section{Theoretical Analysis}

Considering a cylindrical parabolic concentrating collector whose concentrator has an aperture ' $\mathrm{W}_{\mathrm{a}}$ ' and length ' $\mathrm{L}_{\mathrm{c}}$ ' and rim angle ' $\phi_{\text {rim }}$ ' as shown in Figure 1 . The absorber tube has an inner diameter $d_{i}$ and outer diameter $d_{o}$ and it has a concentric glass cover of inner and outer diameters $d_{c i}$ and $\mathrm{d}_{\mathrm{co}}$ respectively. The fluid being heated in the collector has a mass flow rate $\dot{\mathrm{m}}$, inlet temperature $\theta_{\mathrm{fi}}$ and an outlet temperature $\theta_{\text {fo }}$.

The energy equations under steady state condition can be describe by the following expression for an element of thickness $\mathrm{dx}$ of the absorber tube, at distance ' $\mathrm{x}$ ' from inlet,

$d q_{u}=\left[I_{b} r_{b}\left(W_{a}-d_{o}\right) \rho \gamma(\tau \alpha)_{b}+I_{b} r_{b} d_{o}(\tau \alpha)_{b}-\right.$
$\left.U_{L} \pi d_{o}\left(\theta_{p}-\theta_{a}\right)\right] d x$

The left side term in Eq. (1) represents the useful heat gain rate, the first term on right side represents the incident beam radiation absorbed in the absorber tube after reflection, while the second term represents the absorbed incident beam radiation which falls directly on the absorber tube and the third term represents the loss by convection and re-radiation.

The absorbed flux ' $\mathrm{S}$ ' as follows,

$S=I_{b} r_{b} \rho \gamma(\tau \alpha)_{b}+I_{b} r_{b}(\tau \alpha)_{b}\left(\frac{d_{o}}{w_{a}-d_{o}}\right)$

Eq. (1), thus becomes

$d q_{u}=\left(W_{a}-d_{o}\right)\left[S-\frac{U_{L}\left(\theta_{p}-\theta_{a}\right)}{C_{R}}\right] d x$

were, $C_{R}$ is the concentration ratio of the collector, it is the ratio of effective aperture area to the absorber tube area as

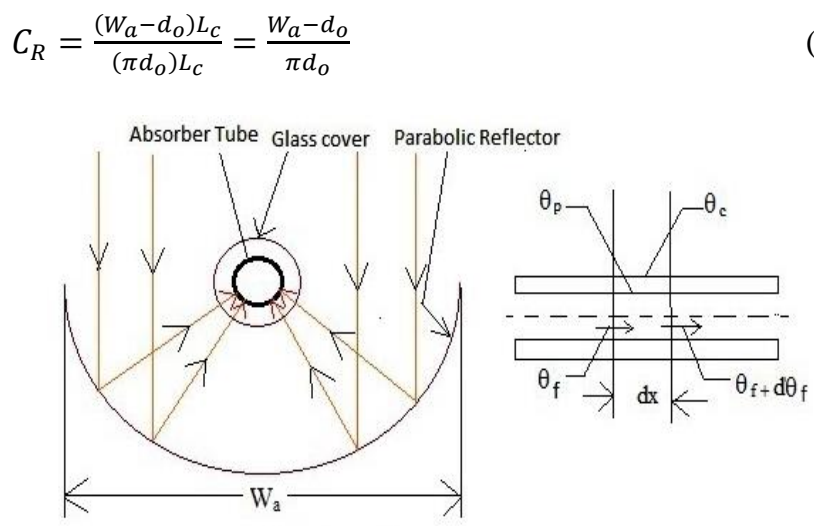

Figure 1.Parabolic trough collector.

The useful heat gain rate $d q_{u}$ can be written as

$d q_{u}=h_{f} \pi d_{i}\left(\theta_{p}-\theta_{f}\right) d x$

where, $h_{f}$ and $\theta_{f}$ are heat transfer coefficient on the inside surface of the tube and local fluid temperature. Combine the Eqs. (3) and (5) and eliminate the absorber tube temperature $\left(\theta_{\mathrm{p}}\right.$ ), the $d q_{u}$ can be expressed as

$d q_{u}=F_{c}^{\prime}\left[S+\left(\theta_{a}-\theta_{f}\right)\left(\frac{U_{L}}{C_{R}}\right)\right]\left(W_{a}-d_{o}\right) d x$

where, $F^{\prime}$ is the collector efficiency factor defined as

$F_{C}^{\prime}=\frac{1}{U_{L}\left[\frac{1}{U_{L}}+\frac{d_{o}}{h_{f} d_{i}}\right]}$

Combining Eqs. (3) and (5), we obtain the differential equation as 
$\frac{d \theta_{f}}{d x}=\frac{F_{c}^{\prime} U_{L} \Pi d_{o}}{\dot{\mathrm{m}} C_{p}}\left[\frac{C_{R} S}{U_{L}}-\left(\theta_{f}-\theta_{a}\right)\right]$

Integrating and using the boundary condition at $\mathrm{x}=0, \theta_{\mathrm{f}}=$ $\theta_{\mathrm{fi}}$ we have the temperature distribution

$\frac{\theta_{f^{-}}\left(\frac{C_{R} S}{U_{L}}+\theta_{a}\right)}{\theta_{f i^{-}}\left(\frac{C_{R} S}{U_{L}}+\theta_{a}\right)}=\exp \left[\frac{-F_{c}^{\prime} U_{L}\left(\pi d_{\mathrm{o}}\right) x}{\dot{\mathrm{m} C} C_{p}}\right]$

The fluid outlet temperature is obtained by putting $\theta_{\mathrm{f}}=\theta_{\mathrm{fo}}$ and $x=L_{c}$ in Eq. (9). Making this substitution and subtracting both sides of the resulting equation from unity, we have

$\left[\frac{\theta_{f o-} \theta_{f i}}{\frac{C_{R} S}{U_{L}}+\theta_{a}+\theta_{f i}}\right]=1-\exp \left[\frac{-F_{C}^{\prime} U_{L}\left(\pi d_{o}\right) L_{c}}{\dot{\mathrm{m} C} C_{P}}\right]$

Thus the useful heat gain rate as

$q_{u}=F_{R}\left(W_{a}-d_{o}\right) L_{c}\left[S-\frac{U_{L}}{C_{R}}\left(\theta_{f i}-\theta_{a}\right)\right]$

where $F_{R}$ is the heat removal factor define by

$F_{R}=\frac{\dot{\mathrm{m}} C_{p}}{U_{L}\left(\pi d_{\mathrm{o}}\right) L_{c}}\left[1-\exp \left\{\frac{-F_{c}^{\prime} U_{L}\left(\pi d_{\mathrm{o}}\right) L_{c}}{\dot{\mathrm{m}} C_{p}}\right\}\right]$

The instantaneous collection efficiency $\eta_{\mathrm{i}}$ is given as

$\eta_{i}=\frac{q_{u}}{\left(I_{b} r_{b}+I_{d} r_{d}\right) W_{a} L_{c}}$

If ground reflected radiation is neglected. The instantaneous collection efficiency can be calculated on the basis of beam radiation alone, is given by

$\eta_{i b}=\frac{q_{u}}{\left(I_{b} r_{b}\right) W_{a} L_{c}}$

\subsection{Overall Loss Coefficient and Heat Transfer Correlations}

For calculating the overall coefficient $\mathrm{U}_{\mathrm{L}}$, the correlations are required for calculating individual heat transfer coefficients. The heat loss rate per unit length can be expressed as

$\frac{q_{l}}{L_{c}}=h_{P-c}\left(\theta_{P m}-\theta_{c}\right) \pi d_{o}+\frac{\sigma \pi \mathrm{d}_{\mathrm{o}}\left(\theta_{\mathrm{pm}}^{4}-\theta_{\mathrm{c}}^{4}\right)}{\left\{\frac{1}{\varepsilon_{\mathrm{p}}}+\frac{\mathrm{d}_{\mathrm{o}}}{\mathrm{d}_{\mathrm{ci}}}\left(\frac{1}{\varepsilon_{\mathrm{c}}}-1\right)\right\}}$

$=h_{P-c} \pi d_{o}\left(\theta_{c}-\theta_{a}\right)+\sigma \pi \mathrm{d}_{\mathrm{co}} \varepsilon_{\mathrm{c}}\left(\theta_{c}^{4}-\theta_{a}^{4}\right)$

Eqs. (15) and (16) are set of two non-liner equations which have to be solved for the unknowns $\frac{q_{l}}{L_{c}}$ and $\theta_{\mathrm{c}}$ after substituting the values of $h_{p-c}$ and $h_{w}$.

\subsection{Heat Transfer Coefficient between the Absorber Tube and the Cover}

The natural convection heat transfer coefficient $h_{p-c}$ for the enclosed annular space between a horizontal absorber tube and a concentric cover is calculated using a correlation byRaithby and Holland [17]

$\frac{k_{e f f}}{k}=0.317\left(R a^{*}\right)^{1 / 4}$
$\left(R a^{*}\right)^{1 / 4}=\frac{\ln \frac{d_{c i}}{d_{o}}}{b^{3 / 4}\left(\frac{1}{d_{o}^{3 / 5}}+\frac{1}{d_{c i}^{3 / 5}}\right)^{5 / 4}}(R a)^{1 / 4}$

The characteristic dimension used for the calculation of the Rayleigh number is the radial gap, $b=\left(d_{c i}-d_{o}\right) / 2$. Properties are evaluated at the mean temperature $\left(\theta_{p m}+\theta_{c}\right) / 2$. It can be noted that the effective thermal conductivity $k_{\text {eff }}$ can't be less than thermal conductivity $k$. Hence $\frac{k_{e f f}}{k}$ is put equal to unity if the Eq. (18) yields a value less than unity.

The relation between the heat transfer coefficient $h_{p-c}$ and the heat exchange rate per unit length can be calculated from the well-known correlation based on the data of Hilpert [19] who conducted experiments on air flowing at right angles across cylinders of various diameters at low levels of free stream turbulence. Hilpert's data can be correlated by the equation

$\mathrm{Nu}=C_{1} \mathrm{Re}^{\mathrm{n}}$

where $C_{1}$ and $\mathrm{n}$ are constant having the following values:

For $40<\operatorname{Re}<4000, \quad C_{1}=0.615, \mathrm{n}=0.466$

For $4000<\operatorname{Re}<40000, \quad C_{1}=0.174, \mathrm{n}=0.618$

For $40000<\operatorname{Re}<40000, \quad C_{1}=0.0239, \mathrm{n}=0.805$

Churchill and Bernstein [19] have made a comprehensive analysis of the data available for cross flow across a cylinder and developed the following correlation

$N u=0.3+\frac{0.62 R e^{1 / 2} \operatorname{Pr}^{1 / 3}}{\left[1+(0.4 / P r)^{2 / 3}\right]^{1 / 4}}\left[1+\left(\frac{R e}{282000}\right)^{5 / 8}\right]^{4 / 5}$

Eq. (21) is valid for all values of Re upto $10^{7}$. For the range $20000<\operatorname{Re}<400000$, Churchill and Bernstein recommended that the last term $\left[1+\left(\frac{\mathrm{Re}}{282000}\right)^{5 / 8}\right]^{4 / 5}$ be modified to $\left[1+\left(\frac{\mathrm{Re}}{282000}\right)^{0.5}\right] . d_{c o}$ is the characteristic dimension to be used in Eqs. (20) and (21). Properties are evaluated at the mean temperature $\left(\theta_{c}+\theta_{a}\right) / 2$.

Eqs. (20) and (21) have been obtained for the cross flow and at low level of turbulence intensity. In practice, the flow may not be right angles and the turbulence intensity in the wind may not be insignificant. As a result, there is an uncertainty in the value of $h_{w}$ predicted by Eqs. (20) and (21). Fortunately, this uncertainty does not affect the value of overall loss coefficient significantly.

\subsection{Heat Transfer Coefficient on the Inside Surface of the Absorber Tube}

The convective heat transfer coefficient $\left(\mathrm{h}_{\mathrm{f}}\right)$ on the inside surface of the absorber tube can be calculated under the assumption that the flow is fully developed. For a Reynolds number less than 2000, the flow is laminar and the heat transfer coefficient may be calculated from equation.

$N u=1.86(\operatorname{RePr})^{0.33}\left(d_{i} / L_{c}\right)^{0.33}$

On the other hand, for a Reynolds number greater than 2000, the flow is turbulent and heat transfer coefficient may be calculated from the well-known Dittus-Boelter equation [20] 
$N u=0.023 \operatorname{Re}^{0.8} \operatorname{Pr}^{0.4}$

The characteristic dimension used for calculating Nusselt number and Reynolds number in Eqs. (22) and (23) is $d_{i}$. Properties are evaluated at the mean temperature $\left(\theta_{\mathrm{fi}}+\theta_{\mathrm{fo}}\right) / 2$.

In most situations, the mass flow rate $\mathrm{m}$ is small and the flow is laminar. Eq. (22) is used. As a consequence, the value of $h_{f}$ is sometimes so small as to adversely affect the value of $F_{R}$. this is particularly true when liquid used is heat transfer oil. These oils have high boiling points, but are characterized by low thermal conductivities and high Prandtl numbers. In such cases, it is desirable to use some kind of augmentative technique to increase the heat transfer coefficient. One of the simplest techniques is to use a serrated twisted tape of width $d_{i}$ inserts all along the inside absorber tube as shown in Figure 2. Change et al [10] derive the generalized correlations to evaluate the Nusselt number in the tube with serrated twisted tape inserts as

$$
N u=\left(0.0118+5.84 e^{-1.83 X}\right) R e^{\left(0.73-0.695 e^{-1.26 X}\right)} \operatorname{Pr} r^{0.33}
$$

where $x=$ tape twist ratio $=H / d_{i}$ and $H=$ length over which the tape is twisted through

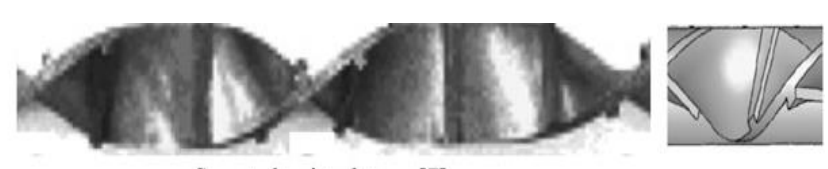

Figure 2 Serrated twisted tape.

\subsection{Analysis of the Parabolic Trough Collector Based on} the Second Law of Thermodynamics

For estimating the second law of efficiency of parabolic trough collector can be written as [23]

$\dot{S}_{g e n}=\left(\frac{Q_{\text {loss }}}{\theta_{a}}-\frac{Q_{*}}{\theta_{s}}+\frac{Q_{u}}{\theta_{f i}}\right)+\left(\frac{m \Delta P}{\rho \theta_{a}}\right)$

Rearranging Eq. (25), the entropy generation rate, $\dot{S}_{g e n}$ of the PTC can be written as

$\dot{\mathrm{S}}_{g e n}=\frac{1}{\theta_{a}}\left(Q_{*}\left(1-\frac{\theta_{a}}{\theta_{s}}\right)-Q_{u}\left(1-\frac{\theta_{a}}{\theta_{f i}}\right)+f \frac{32 m^{3} L}{\pi^{2} \rho^{2} d_{i}^{5}}\right)$

The correlation of the friction factor for plain tube can be expresses as [23]

$f_{p t}=0.376 R e^{-0.259}$

The friction factor when sarreted twisted tape is used is calculated as

$f_{s r}=\left(0.033+0.756 e^{-0.765 x}\right) R e^{\left(0.166-0.235 e^{-0.524 x}\right)}$

The exergy supplied via solar energy to the PTC is calculated by

$\dot{\mathrm{E}}_{s}=Q_{*}\left(1-\frac{\theta_{a}}{\theta_{s}}\right)$

some of this exergy supply is destroyed due to irreversible processes. The exergy destruction $E_{D}$ of the system is calculated by considering its irreversibility, established by the Gouy-Stodola theorem as

$E_{D}=\theta_{a} \dot{\mathrm{S}}_{g e n}$

and refers to the degraded useful energy when real processes are carried out. The exergy efficiency $\eta$ IISRis defined as [23]

$\eta_{I I S R}=1-\frac{E_{D}}{\dot{\mathrm{E}}_{S}}$

The enhancement factor $\Delta \eta_{\text {II }}$ established by considering the second law of thermodynamics as follows,

$\Delta \eta_{I I}=\frac{\eta_{I S R}}{\eta_{I I P t}}$

\section{Results and Discussion}

In the following section, results of thermal performance, such as Nusselt number, heat transfer coefficient, collector efficiency factor, collector heat removal factor, rise in fluid temperature, thermal efficiency, entropy generation rate and exergy efficiency of the proposed solar parabolic trough collector are presented. For performing the calculation of this study a computer program in $\mathrm{C}++$ language was developed, considering the following system, operating and metrological parameters as given in Table 1. The physical properties including density, the specific heat, the dynamic viscosity and the thermal conductivity of Therminol VP-1 has taken at mean temperature.

Table 1. Values of system, operating and metrological parameters.

\section{Width of aperture}

Length of absorber

Inner diameter of absorber

Outer diameter of absorber

Glass cover inner diameter

Glass cover outer diameter

Beam radiation

Diffuse radiation

Intercept factor

Absorber tube emissivity

Absorber tube absorptivity

Transmissivity $\quad 0.85$

Mass flow rate

Solar flux

Tilt factor for beam radiation

Tilt factor for diffuse radiation

Slope

Declination angle

Angle of incidence

Emissivity/absorptivity of glass cover 0.88

Inlet temperature

Wind velocity

Ambient temperature

\begin{tabular}{ll}
$3 \mathrm{~m}$ & \\
$7.8 \mathrm{~m}$ & \\
& $0.0381 \mathrm{~m}$ \\
$0.04315 \mathrm{~m}$ & \\
& $0.0560 \mathrm{~m}$ \\
& $0.0630 \mathrm{~m}$ \\
& $705 \mathrm{~W} / \mathrm{m}^{2}$ \\
& $244 \mathrm{~W} / \mathrm{m}^{2}$ \\
& 0.95 \\
0.95 & \\
0.95 & \\
& \\
& $0.06-0.16 \mathrm{~kg} / \mathrm{s}$ \\
$486.03 \mathrm{~W} / \mathrm{m}^{2}$ \\
1.0143 & \\
0.993 & \\
& $9.625^{\circ}$ \\
$9.415^{\circ}$ & \\
$398^{\circ}$ & \\
0.88 & \\
& $120^{\circ} \mathrm{C}$ \\
& $5.3 \mathrm{~m} / \mathrm{s}$ \\
& $31.9^{\circ} \mathrm{C}$ \\
\hline
\end{tabular}

3.1 Variation of Nusselts Number with Reynolds Number and Heat Transfer Coefficient with Mass Flow Rate for Different Tape Twist Ratio

Figure 3 shows the variation of Nusselt number with Reynolds number and heat transfer coefficient with mass flow rate for different tape twist ratio of serrated twisted tape inserts inside the absorber tube of parabolic trough collector. Results indicated that the Nusselt number obtained from the absorber with inserts is higher than plain absorber for all values of Reynolds number. Also by decreasing the tape twist ratio, the value of Nusselt number is increased. It is clearly seen that the effect of tape inserts increased at high Reynolds number due to intensive mixing of fluid which increased the heat transfer rate and high flow velocity. The effect of mass flow rate on heat transfer coefficient with serrated twisted 
Table 2. Nusselt number and heat transfer coefficient with serrated twisted tape inserts for various values of $x$ and $m$.

\begin{tabular}{|c|c|c|c|c|c|c|c|c|c|c|c|c|c|c|}
\hline \multirow{3}{*}{$\begin{array}{c}\dot{\mathrm{m}} \\
(\mathrm{kg} / \mathrm{s})\end{array}$} & \multirow{2}{*}{\multicolumn{2}{|c|}{ Plain tube }} & \multicolumn{12}{|c|}{ Tape twist ratio $(x)$} \\
\hline & & & \multicolumn{3}{|c|}{$x=1$} & \multicolumn{3}{|c|}{$x=2$} & \multicolumn{3}{|c|}{$x=3$} & \multicolumn{3}{|c|}{$x=4$} \\
\hline & $\mathrm{Nu}_{\mathrm{Pt}}$ & $\mathrm{h}_{\mathrm{Pt}}$ & $\mathrm{Nu}_{\mathrm{SR}}$ & $h_{S R}$ & $Y$ & $\mathrm{Nu}_{\mathrm{SR}}$ & $h_{S R}$ & $Y$ & $\mathrm{Nu}_{\mathrm{SR}}$ & $h_{S R}$ & $Y$ & $\mathrm{Nu}_{\mathrm{SR}}$ & $h_{S R}$ & $Y$ \\
\hline 0.06 & 39.37 & 124.01 & 172.4 & 543 & 4.38 & 140.16 & 441.45 & 3.56 & 103.22 & 325.09 & 2.62 & 97.18 & 306.09 & 2.47 \\
\hline 0.08 & 47.43 & 150.64 & 195.98 & 622.4 & 4.13 & 163.86 & 520.41 & 3.46 & 121.64 & 386.33 & 2.56 & 114.79 & 364.58 & 2.42 \\
\hline 0.10 & 53.95 & 174.59 & 214.49 & 692.5 & 3.98 & 182.71 & 589.86 & 3.39 & 136.35 & 440.19 & 2.53 & 128.87 & 416.04 & 2.39 \\
\hline 0.12 & 62.42 & 202.01 & 236.37 & 763.1 & 3.79 & 206.61 & 666.99 & 3.31 & 155.32 & 501.41 & 2.49 & 147.09 & 474.88 & 2.36 \\
\hline 0.14 & 70.61 & 228.52 & 256.61 & 828.4 & 3.63 & 229.23 & 740.03 & 3.25 & 173.38 & 559.76 & 2.46 & 164.50 & 531.07 & 2.33 \\
\hline 0.16 & 78.57 & 254.28 & 275.53 & 889.5 & 3.51 & 250.82 & 809.73 & 3.19 & 190.74 & 615.77 & 2.43 & 181.24 & 585.09 & 2.31 \\
\hline
\end{tabular}

Note: $\left\{N u_{S R} / N u_{P t}=h_{S R} / h_{P t}=Y\right\}$

tape inserts curves show that as the mass flow increases, heat transfer coefficient for plain as well as serrated twisted tape inserts absorber tube linearly increases. This is because of increases in mass flow rate increase the Reynolds number and heat transfer coefficient. It has been found that heat transfer coefficient increases 4.38 times and 3.51 times with use of serrated twisted tape insert having $\mathrm{x}=1$ at mass flow rate of $0.06 \mathrm{~kg} / \mathrm{s}$ and $0.16 \mathrm{~kg} / \mathrm{s}$ respectively.

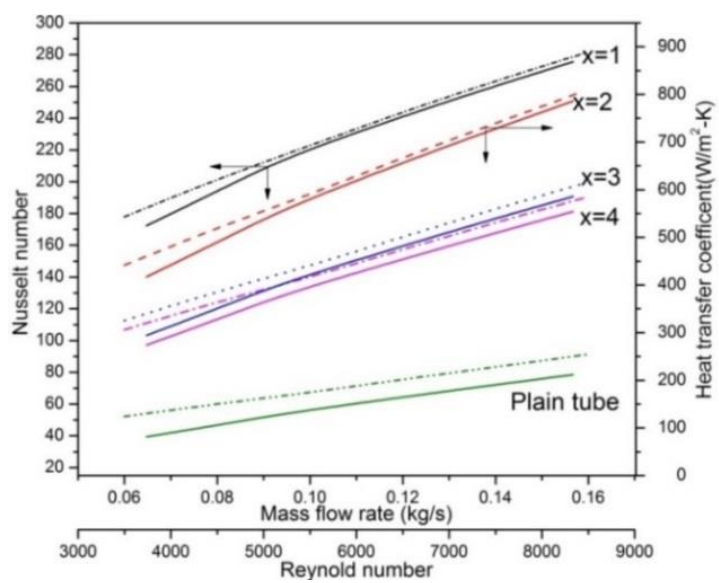

Figure 3. Variation of Nusselt numbers with Reynolds number and heat transfer coefficient with mass flow rate for different tape twist ratio.

The rate of enhancement of Nusselt number increases with increase in Reynolds number. Figure 4 shows the ratio of Nusselt number of serrated twisted tape inserts $\left(\mathrm{Nu}_{\mathrm{SR}}\right)$ to the plain tube $\left(\mathrm{Nu}_{\mathrm{Pt}}\right)$ absorber $\left(\mathrm{Nu}_{\mathrm{SR}} / \mathrm{Nu}_{\mathrm{Pt}}\right)$ as a function of Reynolds number. It has been found that this ratio decreases with increasing Reynolds number and this express the fact that the serrated twisted tape is better for low turbulence flow. Increase in Nusselt numbers and heat transfer coefficients at various values of mass flow rate of fluid for different values of tape twist ratio is given in Table 2 .

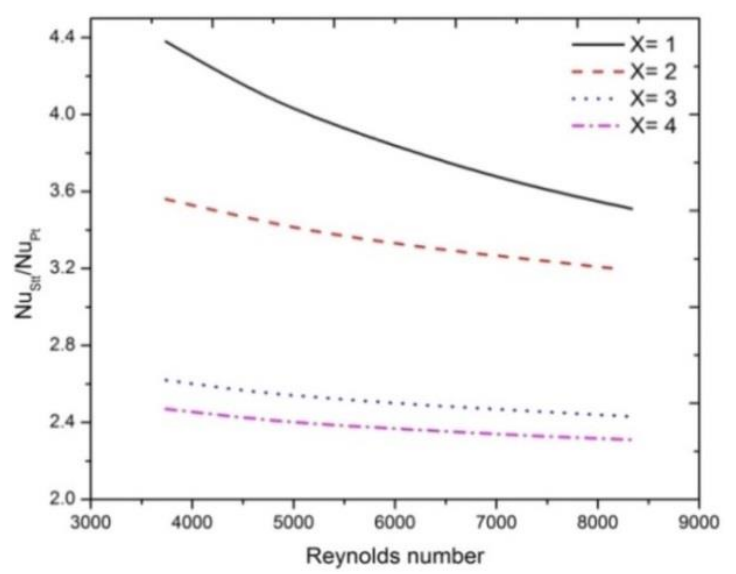

Figure 4.Variation of ratio of Nusselt number $\left(N u_{S R} / N u_{P t}\right)$ with Reynolds number at different tape twist ratio.

\subsection{Effect of Mass Flow Rate on Collector Efficiency Factor and Collector Heat Removal Factor}

Figures 5 and 6 show the collector efficiency factor and collector heat removal factor as a function of mass flow rate of fluid for various values of tape twist ratio of serrated twisted tape inserts for $I_{b}=705 \mathrm{~W} / \mathrm{m}^{2}$ and $I_{d}=244 \mathrm{~W} / \mathrm{m}^{2}$. It is seen from the figures that collector efficiency factor and heat removal factor increases with increase in mass flow rate at all values of the tape twist ratio and also for plain tube. This is due to the fact that increases in mass flow rate of fluid increases the convective heat transfer coefficient and consequently increases the collector efficiency factor and collector heat removal factor. It is also observed that, there is a substantial enhancement of these factors due to decrease in the tape twist ratio. This is because of decrease in twist tape ratio enhances the heat transfer rate due to increase in heat transfer coefficient between tube surface and working fluid by generating turbulent swirling flow. The maximum enhancement in the collector efficiency factor and heat removal factor has been found to be 11.25 $\%$ and $12.13 \%$, respectively, with a tape twist ratio $\mathrm{x}=1$ as compared to plain tube.

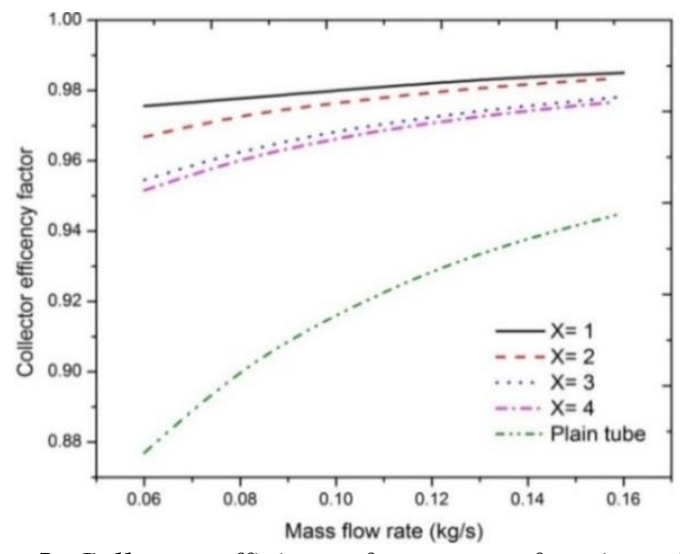

Figure 5. Collector efficiency factor as a function of mass flow rate for different tape twist ratio.

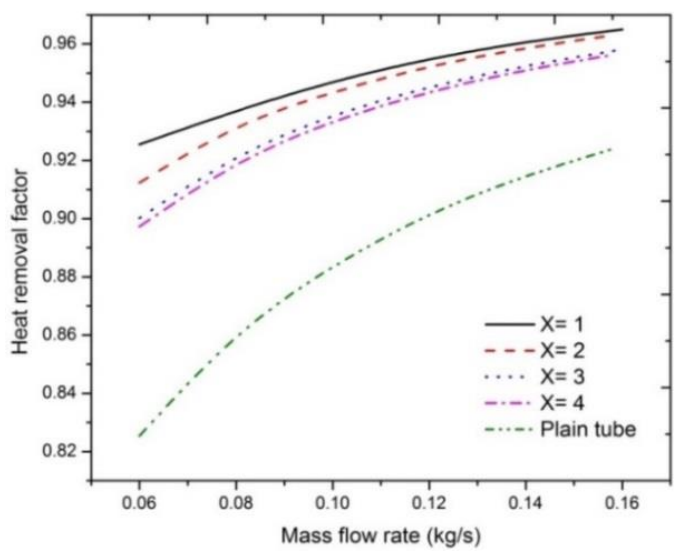

Figure 6. Heat removal factor as a function of mass flow rate at different tape twist ratio of serrated twisted inserts. 
3.3 Effect of Mass Flow Rate on Rise in Fluid Temperature at Different Tape Twist Ratio

Figure 7 shows the variation of the rise in fluid temperature of fluid with function of mass flow rate for various values of tape twist ratio. It is clearly seen from the figure that rise in fluid temperature sharply decreases with increase in mass flow rate and moderately decreases as the mass flow rate increases beyond $0.10 \mathrm{~kg} / \mathrm{s}$. The higher mass flow rate show a less steeper fall because of relatively higher rate of energy collection as a result of higher heat transfer rates and relatively lesser thermal losses. Here, again the most efficient tape twist ratio $(\mathrm{x}=1)$ shows highest temperature rise under similar operating condition because of maximum rate of energy gain for this collector

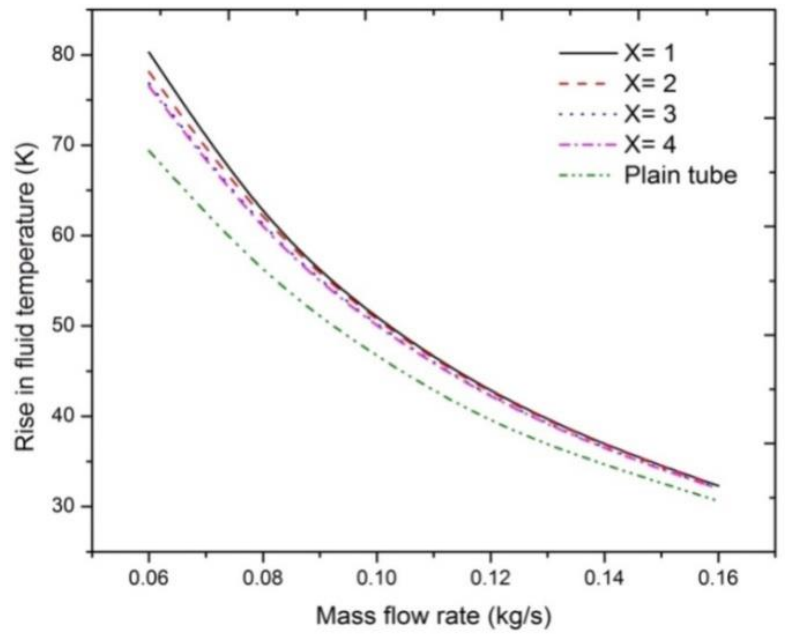

Figure 7. Variation of rise in fluid temperature with mass flow rate at different tape twist ratio.

\subsection{Effect of Mass Flow Rate of Fluid On Thermal Efficiency For Different Twist Tape Ratio}

The effect of mass flow rate of fluid on useful heat gain and collector efficiency has been shown in Figure 8. It is seen from the figure that the useful heat gain as well as efficiency increases with increase in mass flow rate. This is due to enhance heat transfer rate at a higher mass flow rate. It is also seen that useful heat gain and efficiency increases with decrease in tape twist ratio (x). This is because of heat flow rate increases between tube surface and working fluid by generating turbulent swirling flow with decreasing values of tape twist ratio. It has been found that tape twist ratio $x=1$ attains maximum useful heat gain and efficiency in the range of mass flow rate investigated. The percentage enhancement in efficiency with use of theserratedtwist tape insert is shown in Table 3. Inspections of this table show that there is a considerable enhancement in performance with use of serrated twist tape insert. It has been found that the maximum enhancement in efficiency with tape twist ratio $(x=1)$ are $15.7 \%$ and $5.41 \%$ at mass flow rate 0.06 $\mathrm{kg} / \mathrm{s}$ and $0.16 \mathrm{~kg} / \mathrm{s}$ respectively as compared to plain tube. It is also found that the enhancement in efficiency with tape twist ratio $(\mathrm{x}=1)$ are $15.7 \%$ and $5.41 \%$ at flow rate 0.06 $\mathrm{kg} / \mathrm{s}$ and $4.27 \%$ to $5.41 \%$ at higher mass flow efficiency increases from $10.41 \%$ to $15.7 \%$ at lower mass rate $(0.16 \mathrm{~kg} / \mathrm{s})$ respectively as twist tape ratio(x) decreased from 4 to1.

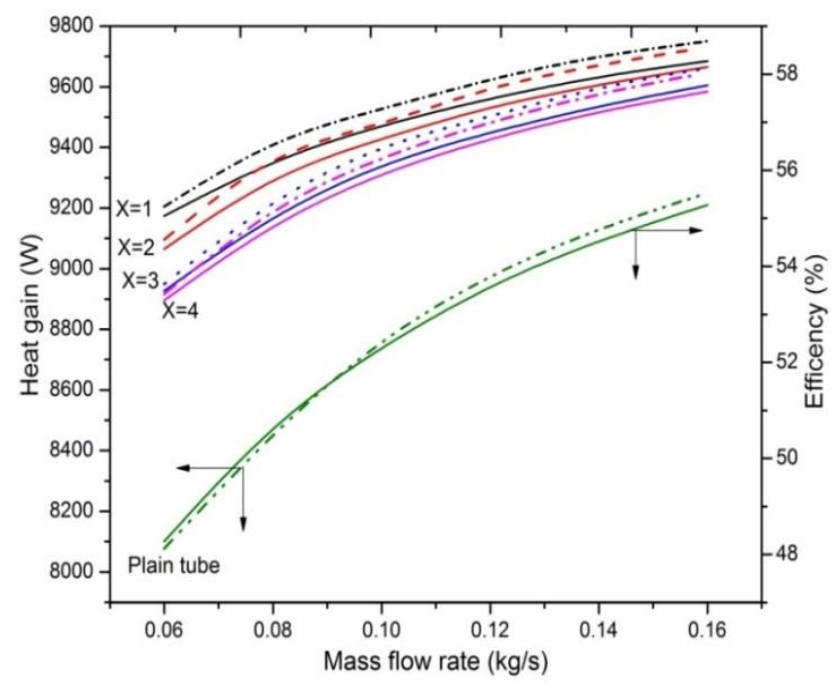

Figure 8. Useful heat gain and efficiency as a function of mass flow rate at different twist tape ratio.

\subsection{Effect of Mass Flow Rate of Fluid with Serrated Twisted Tape Insert on Overall Loss Coefficient}

Figure 9 shows the overall loss coefficient as a function mass flow rate for various value of tape twist ratio. The overall loss coefficient for plain absorber has also been plotted for comparison. The overall loss coefficient for parabolic trough collector with serrated twisted tape as well as plain absorber decreases with the increase in mass flow rate. As obvious, increase in mass flow rate decreases the surface temperature of absorber; there by decreases the value of $U_{L}$. It is also seen from the figure that overall loss coefficient is higher at lower mass flow rate and lower at higher mass flow rate. These types of characteristics behavior observed for all type of serrated twisted tape insert absorbers as well as plain absorber. It may also be noted that rate of decrease of overall loss coefficient is more pronounced at lower mass flow rate as compared to higher mass flow rate. Further, most efficient absorber $(x=1)$ exhibits lowest values of overall loss coefficient in the entire range of mass flow rate investigated.

Table 3. Enhancement in thermal efficiency $\left(\varphi_{t e}\right)$ with serrated twisted tape insert for different values of $x$ 's and $m$ 's.

\begin{tabular}{|c|c|c|c|c|c|c|c|c|c|}
\hline \multirow{2}{*}{$\mathrm{m}(\mathrm{kg} / \mathrm{s})$} & \multirow{2}{*}{ Plain tube } & \multicolumn{9}{|c|}{ Twist tape ratio $(x)$} \\
\cline { 3 - 10 } & & \multicolumn{2}{|c|}{$x=1$} & \multicolumn{2}{c|}{$x=2$} & \multicolumn{2}{c|}{$x=3$} & \multicolumn{2}{c|}{$x=4$} \\
\hline & $\eta_{P t}$ & $\eta_{S R}$ & ${ }^{*} \varphi_{t e}$ & $\eta_{S R}$ & ${ }^{*} \varphi_{\text {te }}$ & $\eta_{S R}$ & ${ }^{*} \varphi_{t e}$ & $\eta_{S R}$ & ${ }^{*} \varphi_{t e}$ \\
\hline 0.06 & 48.27 & 55.85 & 15.7 & 54.36 & 12.62 & 53.49 & 10.81 & 53.29 & 10.40 \\
\hline 0.08 & 50.76 & 56.23 & 10.77 & 55.91 & 10.15 & 55.08 & 8.51 & 54.91 & 8.18 \\
\hline 0.10 & 52.34 & 56.94 & 8.79 & 56.66 & 8.25 & 56.15 & 7.28 & 55.96 & 6.91 \\
\hline 0.12 & 53.62 & 57.50 & 7.24 & 57.33 & 6.92 & 56.79 & 5.91 & 56.66 & 5.67 \\
\hline 0.14 & 54.55 & 57.96 & 6.25 & 57.79 & 5.94 & 57.34 & 5.11 & 57.23 & 4.91 \\
\hline 0.16 & 55.28 & 58.27 & 5.41 & 58.15 & 5.19 & 57.77 & 4.50 & 57.64 & 4.27 \\
\hline
\end{tabular}

${ }^{*}$ Enhancement in thermal efficiency, $\left(\varphi_{t e}\right)=\left(\eta_{S R}-\eta_{P t}\right) / \eta_{P t}$ 


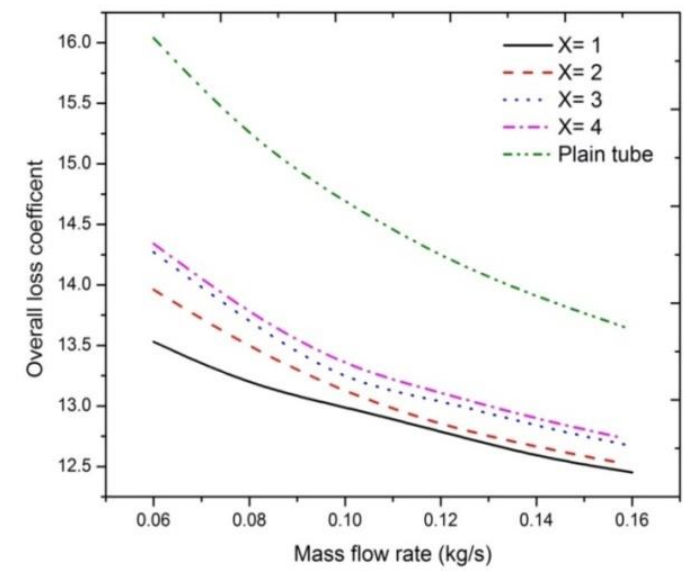

Figure 9. Overall loss coefficient as function of mass flow rate with different tape twist ratio.

\subsection{Effect of Mass Flow Rate of Fluid with Serrated Twisted Tape Insert on Entropy Generation}

Figure 10 shows the variation of the entropy generation with mass flow rate for different values of tape twist ratio. The entropy generation is calculated from Eq. (26). It can be seen from figure that the entropy generation tends to decreases with increasing mass flow rate. For specific mass flow rate at constant inlet temperature, the entropy generation rate increases with decreasing tape twist ratio.

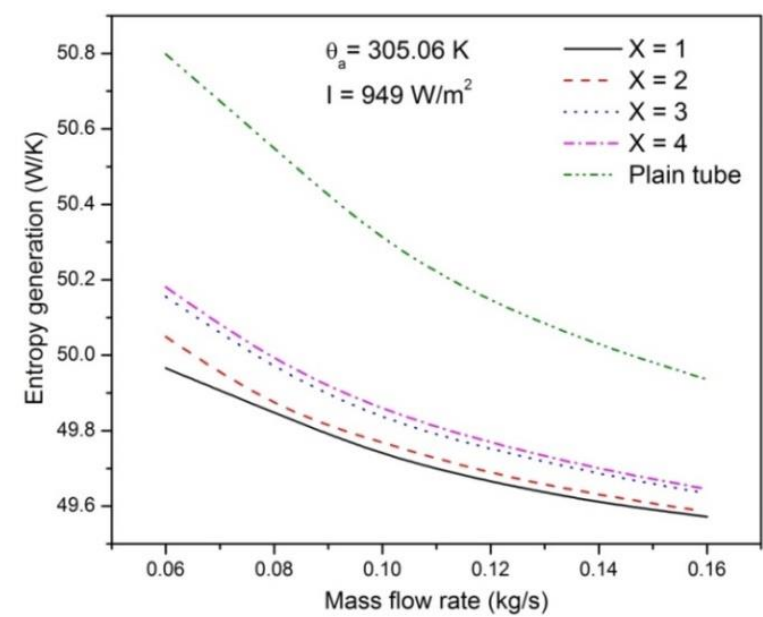

Figure 10. Variation of entropy generation with mass flow rate for different values of tape twist ratio.

\subsection{Effect of Mass Flow Rate on Exergy Efficiency and Enhancement Factor}

Figure 11 shows the variation of the exergy efficiency and enhancement factor i.e. for augmentation of exergy efficiency with mass flow rate for different tape twist ratio. Results of exergy efficiency of plain tube are also plotted for comparison. It is seen from the figure that the exergy efficiency increases and enhancement factor decreases with increase in mass flow rate. It is also observed from the plot that the enhancement in exergy efficiency i.e. enhancement factor is considerably higher at lower mass flow rate and it is lower at higher mass flow rate. This is due fact that at higher mass flow rate the entropy generation decreases. It is also seen that the exergy efficiency and enhancement factor increases with decrease in tape twist ratio for entire mass flow rate investigated. The maximum exergy efficiency with $\mathrm{x}=1$ is observed to be $12.10 \%$ and $12.62 \%$ at lower and higher mass flow rate of $0.06 \mathrm{~kg} / \mathrm{s}$ and $0.16 \mathrm{~kg} / \mathrm{s}$ respectively and corresponding enhancement factor is 1.157 and 1.053 respectively.

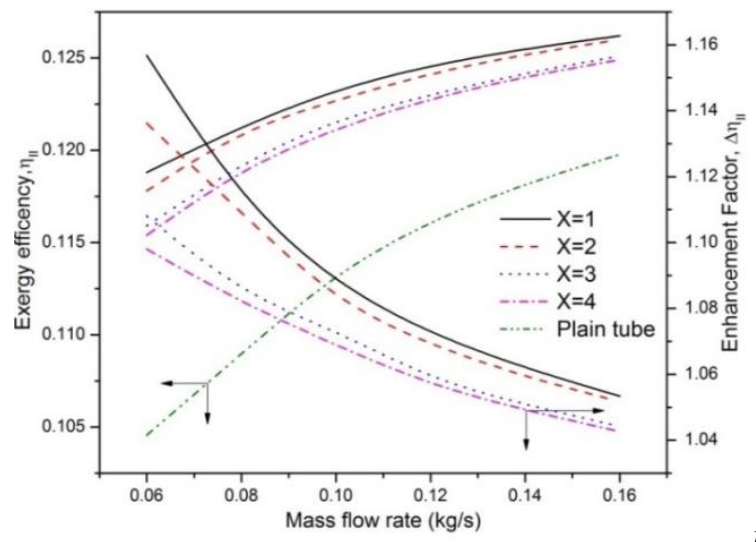

Figure

11. Variation of mass flow rate on exergy efficiency and enhancement factor.

\section{Conclusions}

On the basis of analytical investigations, the following conclusions can be drawn:

- The heat transfer equations have been developed in order to analyze the thermal performance of parabolic trough collector with serrated twisted tape inserts in the absorber tube.

- A computer program in $\mathrm{C}^{++}$language is developed in order to study the effect of system and operating parameters on thermal performance.

- It has been found that the heat transfer coefficient increases 4.38 and 3.51 times to that of plain tube with use of serrated twisted tape inserts $(x=1)$ in the absorber tube of parabolic trough collector at mass flow rate of 0.6 $\mathrm{kg} / \mathrm{s}$ and $0.16 \mathrm{~kg} / \mathrm{s}$ respectively, while corresponding enhancement in thermal efficiency is found to be $15.7 \%$ and $5.41 \%$ respectively.

- Best performance of PTC is achieved with a low tape twist ratio $(x=1)$ operating at low mass flow rate $(0.06$ $\mathrm{kg} / \mathrm{s})$.

- It has been found that entropy generation decreases with increase in mass flow rate and decease in tape twist ratio.

- The exergy efficiency having tape twist ratio, $\mathrm{x}=1$, at mass flow rate of $0.06 \mathrm{~kg} / \mathrm{s}$ and $0.16 \mathrm{~kg} / \mathrm{s}$ has been found to be $12.10 \%$ and $12.62 \%$ respectively while corresponding enhancement factor is found to be 1.157 and 1.053 respectively.

\section{Nomenclature}

$A_{c} \quad$ Surface area of collector, $\mathrm{m}^{2}$

$B \quad$ Radial gap in annulus, $\mathrm{m}$

$C_{p} \quad$ Specific heat, $\mathrm{J} / \mathrm{kg}-\mathrm{k}$

$C_{R} \quad$ Concentration ratio

$d q_{u} \quad$ Useful heat gain rate

$E_{D} \quad$ Exergy destruction

$\dot{E}_{S} \quad$ Exergy supply

$F_{c}^{\prime} \quad$ Collector efficiency factor

$F_{R} \quad$ Collector heat removal factor

$f_{p t} \quad$ Friction factor of plain tube

$f_{S R} \quad$ Friction factor of serrated tape

$h_{f} \quad$ Inside surface heat transfer coefficient, $\mathrm{W} / \mathrm{m}^{2} \mathrm{k}$

$h_{p-c} \quad$ Heat transfer coefficient between absorber plate and glass cover, $\mathrm{W} / \mathrm{m}^{2}-\mathrm{K}$ 
$h_{w} \quad$ Wind heat transfer coefficient, W/m $/ \mathrm{m}^{2}-\mathrm{K}$

$I_{b} \quad$ Incident beam radiation, $\mathrm{W} / \mathrm{m} 2$

$k_{\text {eff }} \quad$ Effective thermal conductivity, W/m-K

$k \quad$ Thermal conductivity of fluid, W/m-k

$H \quad$ Pitch length of twisted tape, $\mathrm{m}$

$L_{c} \quad$ Length of collector, $\mathrm{m}$

$\dot{m} \quad$ Mass flow rate, $\mathrm{kg} / \mathrm{s}$

$\mathrm{Nu} \quad$ Nusselt Number

Pr Prandtl number

$\theta_{\mathrm{a}} \quad$ Ambient temperature, $\mathrm{K}$

$\theta_{\mathrm{c}} \quad$ Temperature of cover, $\mathrm{K}$

$\theta_{\mathrm{f}} \quad$ Local fluid temperature, $\mathrm{K}$

$\theta_{\mathrm{fi}} \quad$ Temperature of fluid at inlet, $\mathrm{K}$

$\theta_{\text {fo }} \quad$ Temperature of fluid at outlet , $\mathrm{K}$

$\theta_{\mathrm{pm}} \quad$ Avg. temperature of absorber plate, $\mathrm{K}$

$Q_{*} \quad$ Solar beam radiation collected by PTC

$\theta_{\mathrm{p}} \quad$ Local temperature of absorber tube, $\mathrm{K}$

$\theta_{\mathrm{s}} \quad$ Apparent temperature of the sun, $\mathrm{K}$

$\mathrm{S} \quad$ Incident solar flux, $\mathrm{W} / \mathrm{m}^{2}$

$\mathrm{W}_{\mathrm{a}} \quad$ Width of aperture, $\mathrm{m}$

$x \quad$ Twist tape ratio

Re Reynolds number

Ra Rayleigh number

$r_{b} \quad$ Tilt factor

Ra* Modified Rayleigh number

$v \quad$ Kinematic viscosity, $\mathrm{m}^{2} / \mathrm{s}$

$\dot{S}_{\text {gen }}$ Entropy generation

\section{Greek symbols}

$\alpha \quad$ Absorptivity of absorber

$\varepsilon_{\mathrm{p}} \quad$ Emissivity of absorber surface

$\varepsilon_{\mathrm{c}} \quad$ Emissivity of cover

$\varphi_{\text {te }} \quad$ Enhancement in thermal efficiency

$\phi_{\mathrm{r}} \quad$ Rim angle

$\rho$ Specular reflectivity of concentrated surface

$\sigma \quad$ Stafan's-Bltzmann constant, W/m $2{ }^{2}-\mathrm{K}^{4}$

$\tau \quad$ Transmissivity of glass cover

$\eta_{\mathrm{i}} \quad$ Instantaneous collection efficiency

$\eta_{\text {SR }} \quad$ Thermal efficiency of serrated tape

$\eta_{\mathrm{pt}} \quad$ Thermal efficiency of plain tube absorber

$\eta_{\text {IISR }} \quad$ Exergy efficiency of serrated twisted tape

$\eta_{\text {IIPt }} \quad$ Exergy efficiency of plain tube

$\Delta \eta_{\text {II }} \quad$ Enhancement factor

\section{Subscripts}

Pt Plain tube

SR Serrated twisted tape

\section{References}

[1] S. Bhattacharyya, S. Saha, S. K Saha, "Laminar flow heat transfer enhancement in a circular tube having integral transverse rib roughness and fitted with centercleared twisted-tape", Experimental Thermal and Fluid Science, 44, 727-735, 2013.

[2] R. Almanza, A. Lentz and G. Jimenez, "Receiver behavior in direct steam generation with parabolic troughs", Solar Energy, 6, 275-278, 1997.

[3] B. S. M. Singh and F. Sulaiman, "Designing a solar thermal cylindrical parabolic trough concentrator by simulation", in International Rio3 Congress, World Climate \& Energy Event, Rio de Janeiro, 143-149, 2003.

[4] S. Ghadirijafarbeiglooa, A. H. Zamzamianb, M. Yaghoubic, "3-D numerical simulation of heat transfer and turbulent flow in a receiver tube of solar parabolic trough concentrator with louvered twisted-tape inserts",
Solar PACES 2013, Energy Procedia, 49, 373-380, 2014.

[5] L. Wang and B. Sunden, "Performance comparison of some tube inserts", Int. Commun. Heat Mass Transfer, 29, pp. 45-56, 2002.

[6] P. K. Nagarajan, P Sivashanmugam, "CFD simulation of heat transfer augmentation in a circular tube fitted with right-left helical inserts with spacer", Int. J. Chem. Eng. Res., 1, 1-11, 2009.

[7] A. S. Yadav, "Effect of half-length twisted-tape turbulators on heat transfer and pressure drop characteristics inside a double pipe U-bend heat exchanger", Jordan Journal of Mechanical and Industrial Engineering, 3(1), 17- 22, 2009.

[8] S. Jaisankar, T. K. Radhakrishnan and K. N. Sheeba, "Experimental studies on heat transfer and friction factor characteristics of thermosyphon solar water heater system fitted with spacer at the trailing edge of twisted-tapes", Applied Thermal Engineering, 29, 12241231, 2009.

[9] J. W. Rose and A. Briggs, "Performance comparison of some tube inserts", Int. Commun. Heat Mass Trans, 29, 45-56, 2002.

[10] S. W. Chang, Y. J. Jan and J. S. Liou, "Turbulent heat transfer and pressure drop in tube fitted with serrated twisted tape", Int. J. Thermal Sciences, 46, 506-518, 2007.

[11] S. Eiamsa-ard, C. Thianpong, P. Eiamsa-ard and P. Promvonge, "Thermal characteristics in a heat exchanger tube fitted with dual twisted tape elements in tandem", Int. Commun. Heat and Mass Transfer, 37, 39-46, 2010.

[12] V. Hejazi, M. A. Akhavan-Behabadi and A. Afshari, "Experimental investigation of twisted-tape inserts performance on condensation heat transfer enhancement and pressure drop", Int. Communications in Heat and Mass Transfer, 37, 1376-1387, 2010.

[13] S. Eiamsa-ard, P. Promvonge, "Performance assessment in a heat exchanger tube with alternate clock wise and counter-clockwise twisted-tape inserts", Int. J. Heat and Mass Transfer 53, 1364-1372, 2010.

[14] P. Ferroni, R. E. Block, N. E. Todreas, and A. E. Bergles, "Experimental evaluation of pressure drop in round tubes provided with physically separated, shortlength twisted-tapes”, Experimental Thermal and Fluid Science 35, 1357-1369, 2011.

[15] V. Zimparov, "Enhancement of heat transfer by a combination of three-start spirally corrugated tubes with a twisted tape", Int. J. Heat and Mass Transfer 44, 551$574,2001$.

[16] J. Guo, A. Fan, X. Zhang and W. Liu, "A numerical study on heat transfer and friction factor characteristics of laminar flow in a circular tube fitted with centercleared twisted-tape", Int. J. Thermal Sciences, 50, 1263-1270, 2011.

[17] C. Thianpong, P. Eiamsa-ard and S. Eiamsa-ard, "Heat transfer and thermal performance characteristics of heat exchanger tube fitted with perforated twisted-tapes", Heat and Mass Transfer, 48, 881-892, 2012. 
[18] G. D. Raithby and K. G. T. Hollands, "A general method of obtaining approximate solutions to laminar and turbulent free convective problems", Advances in Heat Transfer, 11, pp. 265, 1975.

[19] R. Hilpert, "Warmeabgabe von geheizendrahten und rohren, forschgebieteingenieurw," 4, 220, 1933.

[20] S. W. Churchill and M. Bernstein, "A correlation equation for forced convection from gases and liquids to a circular cylinder in cross flow," Journal of Heat Transfer, Trans. ASME, 99, 300, 1977.
[21] S. P. Sukhatme, Solar Energy. Tata McGraw-Hill: New Delhi, India, 2007.

[22] S. W. Hong and A. E. Bergles, "Augmentation of laminar flow heat transfer in tubes by means of twisted tape inserts", Journal of Heat Transfer, Trans. ASME, Paper No. 76-HT-QQ. 251-256,1976.

[23] O. A. Jaramillo, M. Borunda, K. M. Velazquez-lucho and M. Robles, "Parabolic trough solar collector for low enthalpy processes: An analysis of the efficiency enhancement by using twisted tape inserts, Renewable Energy, 93, 125-141, 2016. 